\title{
Role of antioxidants and oxidative stress in the evolution of acute pancreatitis (Review)
}

\author{
VLAD PĂDUREANU ${ }^{1 *}$, DAN NICOLAE FLORESCU ${ }^{2 *}$, RODICA PĂDUREANU $^{3}$, \\ ALICE ELENA GHENEA ${ }^{4}$, DAN IONUT, GHEONEA ${ }^{2}$ and CARMEN NICOLETA OANCEA ${ }^{5}$
}

\author{
Departments of ${ }^{1}$ Internal Medicine and ${ }^{2}$ Gastroenterology, University of Medicine and Pharmacy of \\ Craiova, 200349 Craiova; ${ }^{3}$ Department of Internal Medicine, Emergency Clinical County Hospital of \\ Craiova, 200642 Craiova; Departments of ${ }^{4}$ Bacteriology-Virology-Parasitology and ${ }^{5}$ Analytical Chemistry, \\ University of Medicine and Pharmacy of Craiova, 200349 Craiova, Romania
}

Received September 29, 2021; Accepted October 29, 2021

DOI: $10.3892 / \mathrm{etm} .2022 .11120$

\begin{abstract}
Acute pancreatitis (AP) is a severe disease with a high prevalence and 3 to $15 \%$ mortality worldwide, which can represent an important challenge for the physician. Oxidative stress and antioxidants are involved in AP progression. The mechanisms responsible for the onset and progression of AP are still poorly understood. Previous studies have highlighted the important contribution of antioxidants and oxidative stress in AP. The existence of a relationship between oxidative stress and antioxidants in AP is unquestionable, although a more accurate understanding of the mechanistic pathways involved is required to create a solid basis for potential prevention or treatment strategies. Further investigation is needed to clarify the role of antioxidant status and the severity of AP and to determine the association between oxidative stress and pancreatic enzyme activities. Antioxidant therapy may represent an interesting option for the management of patients with AP, although additional information about the effectiveness of this potential treatment is required.
\end{abstract}

\footnotetext{
Correspondence to: Dr Rodica Pădureanu, Department of Internal Medicine, Emergency Clinical County Hospital of Craiova, 1 Tabaci Street, 200642 Craiova, Romania

E-mail: zegheanurodica@yahoo.com
}

Dr Alice Elena Ghenea, Department of Bacteriology-VirologyParasitology, University of Medicine and Pharmacy of Craiova, 2-4 Petru Rares Street, 200349 Craiova, Romania

E-mail: gaman_alice@yahoo.com

*Contributed equally

Key words: antioxidants, oxidative stress, reactive oxygen species, total antioxidant capacity, acute pancreatitis

\section{Contents}

1. Introduction

2. Methods

3. Antioxidants and oxidative stress

4. Conclusions

\section{Introduction}

Acute pancreatitis (AP) is a severe disease which can represent an important challenge for the physician, especially gastroenterologists and surgeons, and has an incidence of 4.6-100/100,000 persons in Europe (1). AP aetiology includes mainly gallstones and excessive alcohol consumption. The mortality varies from $\sim 3 \%$ for AP cases with interstitial (oedematous) pancreatitis (1) to $15 \%$ for cases with important pancreatic necrosis (2). An international consensus managed to complete a full revision of the Atlanta Classification and definitions (3). This classification identifies two types of the disease, interstitial oedematous pancreatitis and necrotising pancreatitis (3). Inflammation, edema and necrosis of pancreatic tissue are major pathophysiologic processes $(4,5)$. Obstruction of the pancreatic bile duct, pancreatic ischemia, as well as activation of inflammatory cytokines and pancreatic proteases represent the main causes reported in AP (6). An intense inflammatory response $(6,7)$ as consequence of the imbalance between anti-inflammatory mechanisms and pro-inflammatory mediators best describe AP $(8,9)$. The underlying mechanisms of AP pathogenesis remain elusive despite significant progress in the recent years. In addition, no specific therapy exists $(4,10)$. Oxygen radicals play an important role in the development of inflammation in many inflammatory diseases. Previous studies investigated the role of oxidative stress (OS) in AP $(11,12)$. OS appears when there is an imbalance between the antioxidant defence systems and the production of reactive oxygen species (ROS). It is well known that ROS serve numerous important biological functions, including the regulation of redox-sensitive transcription factors, redox-sensitive signal transduction pathways as well as direct interaction with various molecules. Cell damage can be caused by increased oxidative stress either directly or by altering certain signalling pathways. 
For example, in biliary pancreatitis, exposure to biliary acid can cause damage of the pancreatic acinar cells, hence promoting cell apoptosis, but not necrosis (13). Oxygen free radicals have been shown to mediate an important step in the initiation of AP in in vivo models $(11,14)$.

Depletion of ROS leads to low ATP production and favours necrosis, and increased ROS favours apoptosis. In AP, OS appears to play a dual role $(13,14)$. Excessive production of free radicals has numerous negative effects, although they are also synthesized during normal metabolism (14) and serve many physiological roles, such as in the respiratory chain, during phagocytosis, for prostaglandin synthesis and in cytochrome P450 metabolism. Because AP results in increased synthesis of ROS, this phenomenon may be associated with a protective response (14). Thiol-based redox couples, such as reduced glutathione/glutathione disulfide, cysteine/cystine, thioredoxin-reduced/thioredoxin-oxidized form independent signaling networks that selectively regulate developmental events and are closely linked to changes in intracellular redox potentials (15). In human clinical trials, OS in AP is not entirely defined, and whether increased OS might contribute to disease progression from AP to chronic pancreatitis (CP) (16) remains unknown.

Severe AP is associated with poor antioxidant status (AOS) and with significant mortality (16). Xenobiotics are detoxified in the liver (17). Increased exposure to xenobiotics, including nicotine, alcohol and petrochemical fumes, lead to increased OS (18), and pancreatic acinar cells can be exposed to the harmful effects of these free radicals (19). Increased OS can cause cell damage either directly by destroying the cell membrane, or via toxicity from free radical peroxidation products, or via altered signalling pathways, including redox regulation of genes $(20,21)$. Paraoxonase-1 (PON-1) is an esterase associated with high-density lipoprotein cholesterol (HDL-C), which has the ability to prevent or limit lipid peroxidation (22). Previous studies have reported that PON-1 serum levels are diminished in diabetes, cardiovascular diseases and AP, which is correlated with an increase in OS (22-24). The evaluation of total oxidant status, total AOS and ischemia-modified albumin (IMA) are tests used for the evaluation of increased OS. The production of IMA seems to be associated with the production of ROS (25).

The aim of this review was to identify the role of oxidative stress and antioxidants in patients with AP.

\section{Methods}

In the present review, we performed a literature search in Pubmed and Scopus databases by using 'acute pancreatitis', in combination with 'oxidative stress' and 'antioxidants' between 1990 and 2020. We included relevant articles and reviews regarding the implication of oxidative stress and antioxidants in the development of AP. Exclusion criteria were as follows: Studies written in other languages than English, letters to the editor, conference presentations, editorials, comments, opinions and articles without free access.

\section{Antioxidants and oxidative stress}

The mechanisms of AP pathogenesis remain to be fully understood, although the implication of oxidative stress and inflammatory stress is already known. It is considered that increased oxidative stress cannot lead to pancreatitis by itself (12). Free radicals are thought to play a major role in the development of edema in AP, as prophylactic treatment with antioxidants appears to reduce the formation of pancreatic edema (26). However, the role of free radicals in the pathogenesis of pancreatic necrosis is not yet confirmed (26). In addition, free radicals do not appear to have only negative effects on the pancreas, as previous studies suggested that nitric oxide (NO) radical may even protect the pancreas $(14,26,27)$.

The most frequently used biomarker of oxidative stress in the body is malondialdehyde (MDA), which is one of the final products of polyunsaturated fatty acids peroxidation in the cells, while the main markers of antioxidant defence mechanisms of the body are the activity of the superoxide dismutase (SOD2) and the total antioxidant capacity (TAC), which evaluates the amount of free radical scavengers $(16,24,28,29)$. Additional markers that can be used for assessing the AOS is glutathione peroxidase (GPx) activity, while 4-HNE represent another marker of increased OS in the body (16). Plasma level of MDA is a useful additional marker to appreciate the severity of an episode of AP in the very early stages (30). It has been demonstrated that iron may be one of the factors involved in oxidative damage of tissues. In a previous study, Chand et al (31) demonstrated that the interaction between ferritin, hepcidin, interleukin-6 and lipopolysaccharide binding protein can highlight the chronic hyperglycaemia, with some implication in the development of new-onset diabetes after AP. Previous studies suggested that one cause of oxidative stress may be a moderate increase in iron levels in the body (32). Kiziler et al (27) demonstrated that in the early stages of AP, there is a positive correlation between iron concentration and MDA level, suggesting that high iron levels and increased oxidative stress might together cause cellular damage. Norberg et al (33) demonstrated that normal OS controls the synthesis of regulator of calcineurin 1, and this gene might be considered as a marker for the diagnosis of AP. Increased ROS synthesis leads to mitochondria depolarization, decrease ATP production and apoptosis, thus preservation of mitochondrial function is involved in the enhancement of $\mathrm{Ca}^{2+}$ clearance and may decrease the outcome and severity of AP (34).

According to previous studies performed on experimental models of pancreatitis, increased OS is present in AP from the early stage of the disease $(35,36)$. Increased OS is present from the beginning of AP and until the first time of patient hospitalization (37). Circulating concentrations of antioxidant vitamins, such as beta-carotene, vitamin $\mathrm{C}$ and vitamin $\mathrm{E}$, are decreased in AP, which are inversely associated with increased C-reactive protein (CRP) levels (38). Antosiewicz et al (39) reported in experimental models of AP decrease in vitamin $\mathrm{E}$ serum level. Furthermore, the serum concentration of vitamin $\mathrm{E}$ might be decreased in patients with $\mathrm{PA}$, and a negative correlation has been demonstrated between the minimum concentration of vitamin $\mathrm{E}$ and the maximum level of CRP in patients with AP, suggesting that the severity of inflammation may contribute to the vitamin E status (26). Tsai et al (36) reported an association between AP severity and OS. It has been demonstrated that the evolution of AP is characterised by increased lipid peroxidation and reduced glutathione levels and other sulfhydryl compounds in pancreatic tissue (40). 
Patients with AP present with elevated blood levels of superoxide radicals and lipid peroxides (LPO) (41). Lipid peroxidation is most likely secondary to pancreatic inflammation but not a cause and may be associated with the intensity of the systemic inflammatory response, rather than the degree of damage to pancreatic tissue (42). Increased OS was observed in the early stages of AP (43). SOD levels and thiobarbituric acid reactive substances (TBARS) levels are significant higher in patients with AP compared with healthy controls and AOS was demonstrated as poor (43). A favourable evolution of AP was noticed along with the improvement of AOS (43). OS markers and pancreatic enzymes can be used together to evaluate the severity of pancreatitis in AP patients. Higher plasma levels of myeloperoxides and LPO and lower SOD activity were reported in patients with severe AP compared with those with mild AP $(44,45)$. In the early stages of AP, the oxidant-antioxidant balance changes rapidly and is directly correlated with the clinical severity of pancreatitis $(35,46)$.

Previous studies assessing the plasmatic concentration of free radicals in patients with AP and complicated systemic inflammatory response syndrome reported high levels of LPO and NO and decreased levels of beta-carotene, vitamin E, glutathione and reduced activity of GPx $(47,48)$. Another study reported that free radicals can participate to the pathogenesis of AP and SIRS, and that they could play an important role in assessing the severity of AP (49). However, in AP, NO levels increase and cause the activation of the Nuclear factor-kappa $B$ signaling pathway in the dorsal root ganglia, which further inhibits the expression of the kappa opioid receptor leading to the development of pain. Abu-Zidan et al (42) demonstrated that OS markers are positively correlated with the severity of pancreatitis. In addition, AP is characterized by pancreatic glutathione depletion $(50,51)$. Rahman et al (51) reported that decreased concentration of glutathione is associated with increased level of its metabolite cysteinyl glycine, which might induce severe AP.

A previous study demonstrated that serum $\mathrm{PON}-1$ undergoes inhibition and proteolysis during pancreatitis $(52,53)$. In severe cases of AP, serum PON-1 activity diminishes significantly (26). In experimental AP, a decrease in PON-1 activity and serum HDL-C level were reported and were negatively correlated with low-density lipoprotein cholesterol and MDA levels, which were both significantly increased (11). Tvarijonaviciute et al (53) suggested that PON-1 activity is positively correlated with CRP and triglyceride levels and could be considered as a marker to assess AP severity. Yuksekdag et al (54) demonstrated that the low levels of PON-1, HDL-C, SOD and TAC identified in the early stages of AP started to increase after treatment with analgesics, antibiotics and enteral/parenteral nutrition, as well as insulin dose adjustment for diabetic patients and personal medication for arterial hypertension. Furthermore, the initially elevated MDA concentrations decreased, thus suggesting that PON-1, SOD and TAC might represent potential markers to evaluate the clinical course of the disease.

Oxidant levels may increase significantly in patients with severe AP compared with those with mild AP. AP severity is also positively correlated with the lack of a antioxidant reserve, thus leading to increased OS. An increase in OS combined with antioxidant deficiency seems to be implicated in the pathogenesis of recurrent idiopathic AP (16). It is known that melatonin plays a role in activating antioxidant enzymes and neutralizing oxygen radicals (55-57). Previous studies that evaluated the serum melatonin in patients with AP reported that the evolution of the disease was milder in patients with increased serum melatonin levels during the $24 \mathrm{~h}$ following the onset of AP $(58,59)$.

Pancreatic injury during AP is not only due to oxidants alone (40), although oxidants can affect the inflammatory response after AP onset (12). Antioxidant deficiency can affect initially the pancreatic defence mechanism and can subsequently lead to an increase in oxidants levels (41). It is believed that antioxidant levels decrease during inflammation thus leading to the development of pancreatic lesions from AP. Antioxidant blood levels are decreased during severe AP $(42,43)$, and antioxidant supplements have been shown to prevent these decreases in vitro $(44,45)$ and in patients with clinical pancreatitis (35). Previous studies demonstrated that antioxidant treatment may reduce the pain in patients with CP $(16,60)$. Furthermore, antioxidant therapy can also ameliorate extrapancreatic complications, including peritonitis, arterial hypotension and ascites, thus improving the course of the disease (61). Although antioxidant therapy appears to have a favourable effect in $\mathrm{CP}$, a previous study suggested that antioxidant agents would not bring any benefit in AP (14).

At present, antioxidants are not used in the standard treatment of patients with AP, which emphasizes the need for further studies (62). Escobar et al (59) reported that oxypurinol combined with pentoxifylline could decrease OS in pancreatic tissue, as oxypurinol protects glutathione from oxidation and pentoxyfilline inhibits glutathione depletion. A study by Siriwardena et al (28) demonstrated that therapy using selenium, vitamin $\mathrm{C}$ and n-acetylcysteine prevents the decrease in antioxidant levels but does not seem to influence the evolution of patients with AP, the period of hospitalization and organ dysfunction. Furthermore, a study suggested that intravenous administration of antioxidants, such as n-acetylcysteine, selenium or vitamin $\mathrm{C}$, to patients with AP with two or more organ dysfunctions may increase mortality. The authors suggested that systemic antioxidant weariness that is usually simultaneous with severe AP is an essential part of the regulatory mechanism that aids the activation of the anti-inflammatory cytokine response $(57,58)$. However, another study suggested that selenium and vitamin $\mathrm{C}$ do not seem to have this effect, although further investigation is required (63). Uden et al (62) evaluated the effect of administering vitamin $\mathrm{C}$, vitamin $\mathrm{E}$, beta carotene, selenium and methionine on recurrent pancreatitis and demonstrated that patients receiving the antioxidant therapy did not suffer a recurrent attack during the follow-up period and suffered from less pain compared with patients receiving the placebo. Although it was reported that antioxidant therapy might have favourable effects in cases of spontaneous AP, this therapy does not appear to influence post-endoscopic retrograde cholangiopancreatography AP.

\section{Conclusions}

Although multiple studies have demonstrated the important role of increased OS in the pathophysiology of $\mathrm{CP}$, the association between AP and OS requires further investigation, as numerous contradictory results still exist. In the literature, 
there are few clinical studies about the implication of antioxidants in the mechanisms of AP. Future studies must investigate the association between increased OS and the activity of pancreatic enzymes. The inflammatory process and the severity of AP may be closely associated with oxygen-derived free radicals. Future studies are required to clarify the link between the AOS and the severity of AP. One good marker for determining the severity of the disease is the plasma level of LPO. Assessment of GPx, 4-HNE and ferric reducing ability of plasma may be considered as useful biological markers in cases of idiopathic recurrent AP.

The AOS is deficient and OS is increased in patients with idiopathic recurrent AP. In these patients, one therapeutic option may be the supplementation in antioxidants, as previous studies suggested that this therapy might prevent the development of CP. However, although this antioxidant therapy represents an exciting option for the treatment of patients with AP, further evaluation of its effectiveness is required.

\section{Acknowledgements}

Not applicable.

\section{Funding}

No funding was received.

\section{Availability of data and materials}

Not applicable.

\section{Authors' contributions}

VP, DNF, RP, AEG, DIG and CNO contributed equally to the acquisition, analysis and systematization of data, manuscript writing and critical revision of it for important intellectual content. All authors read and approved the final version of the manuscript.

\section{Ethics approval and consent to participate}

Not applicable.

\section{Patients consent for publication}

Not applicable.

\section{Competing interests}

The authors declare that they have no competing interests.

\section{References}

1. Singh VK, Bollen TL, Wu BU, Repas K, Maurer R, Yu S, Mortele KJ, Conwell DL and Banks PA: An assessment of the severity of interstitial pancreatitis. Clin Gastroenterol Hepatol 9: 1098-1103, 2011.

2. van Santvoort HC, Bakker OJ, Bollen TL, Besselink MG, Ahmed Ali U, Schrijver AM, Boermeester MA, van Goor H, Dejong $\mathrm{CH}$, van Eijck $\mathrm{CH}$, et al: A conservative and minimally invasive approach to necrotizing pancreatitis improves outcome Gastroenterology 141: 1254-1263, 2011.
3. Banks PA, Bollen TL, Dervenis C, Gooszen HG, Johnson CD, Sarr MG, Tsiotos GG and Vege SS; Acute Pancreatitis Classification Working Group: Classification of acute pancreatitis - 2012: Revision of the Atlanta classification and definitions by international consensus. Gut 62: 102-111, 2013.

4. Pandol SJ, Saluja AK, Imrie CW and Banks PA: Acute pancreatitis: Bench to the bedside. Gastroenterology 132: 1127-1151, 2007.

5. Maléth J, Rakonczay Z Jr, Venglovecz V, Dolman NJ and Hegyi P: Central role of mitochondrial injury in the pathogenesis of acute pancreatitis. Acta Physiol(Oxf) 207: 226-235, 2013.

6. Ozhan G, Sari FM, Vefai M, Yanar HT and Alpertunga B: Acute pancreatitis is associated with Ser608Leu iNOS polymorphism. Folia Biol (Praha) 58: 256-260, 2012.

7. Pădureanu V, Boldeanu MV, Streaţă I, Cucu MG, Siloşi I, Boldeanu L, Bogdan M, Enescu AS,, Fortofoiu M, Enescu A, et al: Determination of VEGFR-2 (KDR) $604 \mathrm{~A}>\mathrm{G}$ polymorphism in pancreatic disorders. Int J Mol Sci 18: 439, 2017.

8. Goldie AS, Fearon KC, Ross JA, Barclay GR, Jackson RE, Grant IS, Ramsay G, Blyth AS and Howie JC: Natural cytokine antagonists and endogenous anti endotoxin core antibodies in sepsis syndrome. JAMA 274: 172-177, 1995.

9. He C, Zhang L, Shi W, Liang X, Ye Z, Zhang B and Liu S: Coupled plasma filtration adsorption combined with continuous veno-venous hemofiltration treatment in patients with severe acute pancreatitis. J Clin Gastroenterol 47: 62-68, 2013.

10. Sah RP and Saluja A: Molecular mechanisms of pancreatic injury. Curr Opin Gastroenterol 27: 444-451, 2011.

11. Schoenberg MH, Birk D and Beger HG: Oxidative stress in acute and chronic pancreatitis. Am J Clin Nutr 62 (6 Suppl): 1306S-1314S, 1995.

12. Johnson CD: Antioxidants in acute pancreatitis. Gut 56: 1344-1345, 2007.

13. Dryden GW Jr, Deaciuc I, Arteel G and McClain CJ: Clinical implications of oxidative stress and antioxidant therapy. Curr Gastroenterol Rep 7: 308-316, 2005.

14. Booth DM, Murphy JA, Mukherjee R, Awais M, Neoptolemos JP, Gerasimenko OV, Tepikin AV, Petersen OH, Sutton R and Criddle DN: Reactive oxygen species induced by bile acid induce apoptosis and protect against necrosis in pancreatic acinar cells. Gastroenterology 140: 2116-2125, 2011.

15. Harris C and Hansen JM: Oxidative stress, thiols, and redox profiles. Methods Mol Biol 889: 325-346, 2012.

16. Bopanna S, Nayak B, Prakash S, Shalimar, Mahapatra SJ and Garg PK: Increased oxidative stress and deficient antioxidant levels may be involved in the pathogenesis of idiopathic recurrent acute pancreatitis. Pancreatology 17: 529-533, 2017.

17. Lu Y and Cederbaum AI: CYP2E1 and oxidative liver injury by alcohol. Free Radic Biol Med 44: 723-738, 2008.

18. Park BK, Kitteringham NR, Pirmohamed M and Tucker GT: Relevance of induction of human drug-metabolizing enzymes: Pharmacological and toxicological implications. Br J Clin Pharmacol 41: 477-491, 1996.

19. Tandon RK and Garg PK: Oxidative stress in chronic pancreatitis: Pathophysiological relevance and management. Antioxid Redox Signal 15: 2757-2766, 2011.

20. Telek G, Regoly-Merei J, Kovacs GC, Simon L, Nagy Z, Hamar J and Jakab F: The first histological demonstration of pancreatic oxidative stress in human acute pancreatitis Hepatogastroenterology 48: 1252-1258, 2001.

21. Valko M, Leibfritz D, Moncol J, Cronin MT, Mazur M and Telser J: Free radicals and antioxidants in normal physiological functions and human disease. Int J Biochem Cell Biol 39: 44-84, 2007.

22. Tsuzura S, Ikeda Y, Suehiro T, Ota K, Osaki F, Arii K, Kumon Y and Hashimoto K: Correlation of plasma oxidized low-density lipoprotein levels to vascular complications and human serum paraoxonase in patients with type 2 diabetes. Metabolism 53: 297-302, 2004.

23. Kodydkova J, Vavrova L, Stankova B, Macasek J, Krechler T and Zak A: Antioxidant status and oxidative stress markers in pancreatic cancer and chronic pancreatitis. Pancreas 42: 614-621, 2013.

24. Baser H, Can U, Karasoy D, Ay AS, Baser S, Yerlikaya FH and Ecirli S: Evaluation of oxidant/anti-oxidants status in patients with mild acute-pancreatitis. Acta Gastroenterol Belg 79: 23-28, 2016.

25. Petrov MS: Therapeutic implications of oxidative stress in acute and chronic pancreatitis. Curr Opin Clin Nutr Metab Care 13: $562-568,2010$. 
26. Andican G, Gelisgen R, Unal E, Tortum OB, Dervisoglu S, Karahasanoglu T and Burçak G: Oxidative stress and nitric oxide in rats with alcohol-induced acute pancreatitis. World J Gastroenterol 11: 2340-2345, 2005.

27. Kiziler AR, Aydemir B, Gulyasar T, Unal E and Gunes P: Relationships among iron, protein oxidation and lipid peroxidation levels in rats with alcohol-induced acute pancreatitis. Biol Trace Elem Res 124: 135-143, 2008.

28. Siriwardena AK, Mason JM, Balachandra S, Bagul A, Galloway S, Formela L, Hardman JG and Jamdar S: Randomised, double blind, placebo controlled trial of intravenous antioxidant (n-acetylcysteine, selenium, vitamin C) therapy in severe acute pancreatitis. Gut 56: 1439-1444, 2007.

29. Armstrong JA, Cash N, Soares PM, Souza MH, Sutton R and Criddle DN: Oxidativestress in acute pancreatitis: Lost in translation? Free Radic Res 47: 917-933, 2013.

30. Dabrowski A and Gabryelewicz A: Oxidative stress. An early phenomenon characteristic of acute experimental pancreatitis. Int J Pancreatol 12: 193-199, 1992.

31. Chand SK, Singh RG, Pendharkar SA and Petrov MS: Iron: A strong element in the pathogenesis of chronic hyperglycaemia after acute pancreatitis. Biol Trace Elem Res 183: 71-79, 2018.

32. Dabrowski A and Gabryelewicz A: Nitric oxide contributes to multiorgan oxidative stress in acute experimental pancreatitis. Scand J Gastroenterol 29: 943-948, 1994.

33. Norberg KJ, Nania S, Li X, Gao H, Szatmary P, Segersvärd R, Haas S, Wagman A, Arnelo U, Sutton R, et al: RCAN1 is a marker of oxidative stress, induced in acute pancreatitis. Pancreatology 18: 734-741, 2018.

34. Braganza JM, Scott P, Bilton D, Schofield D, Chaloner C, Shiel N, Hunt LP and Bottiglieri T: Evidence for early oxidative stress in acute pancreatitis. Clues for correction. Int J Pancreatol 17: 69-81, 1995.

35. Curran FJ, Sattar N, Talwar D, Baxter JN and Imrie CW: Relationship of carotenoid and vitamins $\mathrm{A}$ and $\mathrm{E}$ with the acute inflammatory response in acute pancreatitis. Br J Surg 87: 301-305, 2000

36. Tsai K, Wang SS, Chen TS, Kong CW, Chang FY, Lee SD and Lu FJ: Oxidative stress: An important phenomenon with pathogenetic significance in the progression of acute pancreatitis. Gut 42: 850-855, 1998.

37. Thareja S, Bhardwaj P, Sateesh J and Saraya A: Variations in the levels of oxidative stress and antioxidants during early acute pancreatitis. Trop Gastroenterol 30: 26-31, 2009.

38. Park BK, Chung JB, Lee JH, Suh JH, Park SW, Song SY, Kim H, Kim KH and Kang JK: Role of oxygen free radicals in patients with acute pancreatitis. World J Gastroenterol 9: 2266-2269, 2003

39. Antosiewicz J, Popinigis J, Ishiguro $\mathrm{H}$, Hayakawa $\mathrm{T}$ and Wakabayashi T: Cerulein-induced acute pancreatitis diminished vitamin $E$ concentration in plasma and increased in the pancreas. Int J Pancreatol 17: 231-236, 1995.

40. Folch E, Gelpi E, Rosello-Catafau J and Closa D: Free radicals generated by xanthine oxidase mediate pancreatitis-associated organ failure. Dig Dis Sci 43: 2405-2410, 1998.

41. Dziurkowska-Marek A,Marek TA,Nowak A,Kacperek-Hartleb T, Sierka E and Nowakowska-Duława E: The dynamics of the oxidant-antioxidant balance in the early phase of human acute biliary pancreatitis. Pancreatology 4: 215-222, 2004.

42. Abu-Zidan FM, Bonham MJ and Windsor JA: Severity of acute pancreatitis: A multivariate analysis of oxidative stress markers and modified Glasgow criteria. Br J Surg 87: 1019-1023, 2000.

43. Franco-Pons N, Marsillach J, Joven J, Camps J and Closa D: Serum paraoxonase undergoes inhibition and proteolysis during experimental acute pancreatitis. J Gastrointest Surg 12: 891-899, 2008

44. Rau B, Poch B, Gansauge F, Bauer A, Nüssler AK, Nevalainen T, Schoenberg MH and Begeret HG: Pathophysiologic role of oxygen free radicals in acute pancreatitis: Initiating event or mediator of tissue damage? Ann Surg 231: 352-360, 2000

45. Solakoglu T, Koseoglu H, Isikoglu S, Erel O and Ersoy O: Association between antioxidants and mild acute pancreatitis. Arab J Gastroenterol 18: 201-205, 2017.
46. Scott P, Bruce C, Schofield D, Shiel N, Braganza JM and McCloy RF: Vitamin C status in patients with acute pancreatitis. Br J Surg 80: 750-754, 1993.

47. Schoenberg MH, Buchler M, Gaspar M, Stinner A, Younes M, Melzner I, Bültmann B and Beger HG: Oxygen free radicals in acute pancreatitis of the rat. Gut 31: 1138-1143, 1990.

48. Cuzzocrea S, Genovese T, Mazzon E, Di Paola R, Muià C, Britti D and Salvemini D: Reduction in the development of cerulein-induced acute pancreatitis by treatment with M40401, a new selective superoxide dismutase mimetic. Shock 22: 254-261, 2004.

49. Virlos IT, Mason J, Schofield D, McCloy RF, Eddleston JM and Siriwardena AK: Intravenous n-acetylcysteine, ascorbic acid and selenium-based anti-oxidant therapy in severe acute pancreatitis. Scand J Gastroenterol 38: 1262-1267, 2003.

50. Schulz HU, Niederau C, Klonowski-Stumpe H, Halangk W, Luthen R and Lippert H: Oxidative stress in acute pancreatitis. Hepatogastroenterology 46: 2736-2750, 1999.

51. Rahman SH, Srinivasan AR and Nicolaou A: Transsulfuration pathway defects and increased glutathione degradation in severe acute pancreatitis. Dig Dis Sci 54: 675-682, 2009.

52. Sweiry JH and Mann GE: Role of oxidative stress in the pathogenesis of acute pancreatitis. Scand J Gastroenterol Suppl 219: 10-15, 1996

53. Tvarijonaviciute A, García-Martínez JD, Caldin M, Martínez-Subiela S, Tecles F, Pastor J and Ceron JJ: Serum paraoxonase 1 (PON1) activity in acute pancreatitis of dogs. J Small Anim Pract 56: 67-71, 2015.

54. Yuksekdag S, Yuksel E, Topcu A, Karaagac N, Uzun H, Kiziler AR, Ezberci F and Unal E: Serum paraoxonase (a high-density lipoprotein-associated lipophilic antioxidant) activity in clinical follow-up of patients with acute pancreatitis, with particular emphasis on oxidative stress parameters and lipid profile: A prospective pilot trial. Libyan J Med 14: 1595955 , 2019.

55. Dröge W: Free radicals in the physiological control of cell function. Physiol Rev 82: 47-95, 2002.

56. Abu-Hilal M, McPhail MJ, Marchand L and Johnson CD: Malondialdehyde and superoxide dismutase as potential markers of severity in acute pancreatitis. JOP 7: 185-192, 2006.

57. Bjelakovic G, Nikolova D, Gluud LL, Simonetti RG and Gluud C: Mortality in randomized trials of antioxidant supplements for primary and secondary prevention: Systematic review and meta-analysis. JAMA 297: 842-857, 2007.

58. Que RS, Cao LP, Ding GP, Hu JA, Mao KJ and Wang GF: Correlation of nitric oxide and other free radicals with the severity of acute pancreatitis and complicated systemic inflammatory response syndrome. Pancreas 39: 536-540, 2010.

59. Escobar J, Pereda J, Arduini A, Sandoval J, Moreno ML, Pérez S, Sabater L, Aparisi L, Cassinello N, Hidalgo J, et al: Oxidative and nitrosative stress in acute pancreatitis. Modulation by pentoxifylline and oxypurinol. Biochem Pharmacol 83: 122-130, 2012.

60. Herbert V, Shaw S, Jayatilleke E and Stopler-Kasdan T: Most free-radical injury is iron-related: it is promoted by iron, hemin, holoferritin and vitamin $\mathrm{C}$, and inhibited by desferoxamine and apoferritin. Stem Cells 12: 289-303, 1994.

61. Robles L, Vaziri ND and Ichii H: Role of Oxidative stress in the pathogenesis of pancreatitis: Effect of antioxidant therapy. Pancreat Disord Ther 3: 112, 2013

62. Uden S, Bilton D, Nathan L, Hunt LP, Main C and Braganza JM: Antioxidant therapy for recurrent pancreatitis: Placebo-controlled trial. Aliment Pharmacol Ther 4: 357-371, 1990.

63. Rodriguez C, Mayo JC, Sainz RM, Antolín I, Herrera F, Martín V and Reiter RJ: Regulation of antioxidant enzymes: A significant role for melatonin. J Pineal Res 36: 1-9, 2004.

This work is licensed under a Creative Commons Attribution-NonCommercial-NoDerivatives 4.0 International (CC BY-NC-ND 4.0) License. 